\title{
Irritant hand dermatitis during the COVID-19 outbreak
}

\author{
Gita Faghihi', Yalda Radan², Mohammad Reza Radan³
}

${ }^{1}$ Skin Diseases and Leishmaniasis Research Center, Department of Dermatology, Isfahan University of Medical Sciences, Isfahan, Iran, ${ }^{2}$ Medical student, Isfahan School of Medicine, Isfahan University of Medical Sciences, Isfahan, Iran, ${ }^{3}$ Sadaf Dermatology Clinic, Isfahan Iran

Corresponding author: Prof. Gita Faghihi, E-mail: g_faghihi@med.mui.ac.ir

Sir,

Coronaviruses are incapable of penetrating healthy skin tissue, which is a protective barrier against COVID-19 viral infections [1]. Contaminated hands can, however, transmit viruses to the mucosal surfaces of the eyes and the nasal and oral cavities [2]. For this reason, proper handwashing is necessary and very much important during the times of the COVID-19 outbreak.

At the same time, obsessive and compulsive behavior in hand hygiene may easily lead to irritant contact dermatitis. This is more commonly observed in some occupations than others, such as health care workers, food handlers, and hairdressers [3]. The prevalence of hand eczema in those who use excessive amounts of disinfectant solutions, detergents, and alcohol-based rubs is rising [4].

This, of course, is not to disregard hand hygiene, but to imply that a more appropriate and thoughtful handwashing process must be adopted in ensuring safety during the COVID-19 pandemic. Irritation of hands can even lead to the triggering of other dermatoses [5]. Due to the appearance of fissures and irritated eczematous areas, the threat of secondary bacterial infection becomes a concern [6].

We have seen abundant cases of atopy, psoriasis, and lichen planus with exaggerated hand dermatosis since the beginning of the COVID-19 outbreak.

Besides direct injury from chemical irritants and wet work to the hands, emotional stress (COVID-19 nosophobia) and a disquieting mental disposition help to exacerbate pruritus and inflammation of the skin.
We have seen numerous patients with hand eczema for the first time in their lives amid the coronavirus outbreak, who, despite enjoying good general health and having received PCR tests with negative results, are obsessively concerned with having acquired a coronavirus infection from family members, friends, or colleagues. Examinations of damaged skin have often revealed symptoms of eczema, such as coarse and chapped skin, scaly erythematous plaques, dry patches on dorsal surfaces, and painful fissures on the fingertips, with impending impetiginized eczema over local areas of skin injury (Fig. 1).

The measures to follow, thus, include the use of emollient creams after handwashing and less frequent handwashing sessions by using protective gloves in routine daily activities and using alcoholbased hand rubs with moisturizing ingredients (humectants) [7].

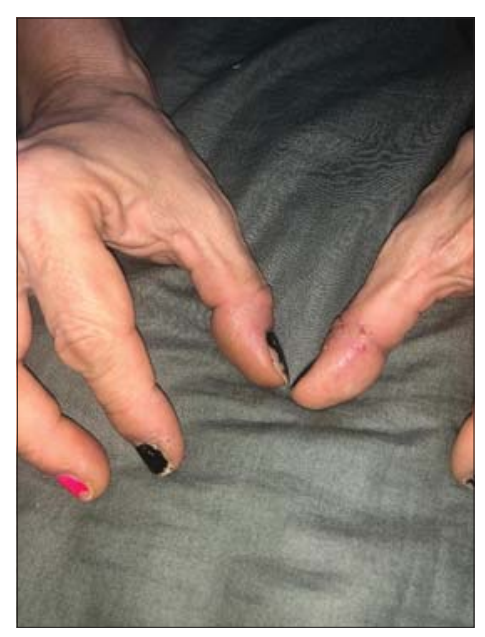

Figure 1: Painful cracks on the fingers, irritated periungual folds, and yellow crusts on eczematous lesions indicating superinfection. 


\section{Consent}

The examination of the patient was conducted according to the Declaration of Helsinki principles.

The authors certify that they have obtained all appropriate patient consent forms. In the form the patient(s) has/have given his/her/ their consent for his/her/their images and other clinical information to be reported in the journal. The patients understand that their names and initials will not be published and due efforts will be made to conceal their identity, but anonymity cannot be guaranteed.

\section{REFERENCES}

1. Darlenski R, Tsankov N. Covid-19 pandemic and the skin - What should dermatologists know? Clin Dermatol. 2020 Mar 24.

2. Singh M, Pawar M, Bothra A, Choudhary N. Overzealous hand hygiene during the COVID 19 pandemic causing an increased incidence of hand eczema among general population. J Am Acad Dermatol. 2020;S0190-9622:30660-5.

3. Callahan A, Baron E, Fekedulegn D, Kashon M, Yucesoy B,
Johnson VJ, et al. Winter season, frequent hand washing, and irritant patch test reactions to detergents are associated with hand dermatitis in health care workers. Dermatitis. 2013;24:170-5.

4. Kampf G, Kramer A. Epidemiologic background of hand hygiene and evaluation of the most important agents for scrubs and rubs. Clin Microbiol Rev. 2004;17:863-93.

5. Kantor R, Silverberg JI. Environmental risk factors and their role in the management of atopic dermatitis. Expert Rev Clin Immunol. 2017;13:15-26.

6. Wang X, Shi XD, Li LF, Zhou P, Shen YW. Classification and possible bacterial infection in outpatients with eczema and dermatitis in China: A cross-sectional and multicenter study. Medicine (Baltimore). 2017;96:e7955.

7. Davarnia G, Khaki A. Recommendations regarding skin care for perventing hand eczema on COVID-19. Crescent J Med Biol Scien. 2020;7:140-1.

Copyright by Gita Faghihi, et al. This is an open access article distributed under the terms of the Creative Commons Attribution License, which permits unrestricted use, distribution, and reproduction in any medium, provided the original author and source are credited.

Source of Support: Nil, Conflict of Interest: None declared. 